\begin{tabular}{|c|c|}
\hline \multirow{3}{*}{ 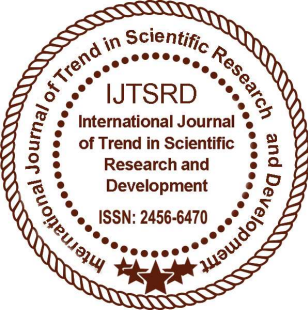 } & $\begin{array}{l}\text { International Journal of Trend in Scientific } \\
\text { Research and Development (IJTSRD) }\end{array}$ \\
\hline & International Open Access Journal \\
\hline & ISSN No: 2456 - 6470 | www.ijtsrd.com | Volume - 2 | Issue - 4 \\
\hline
\end{tabular}

\title{
Science News in African Newspapers has Less Space Share than Asia: An Epistemological Case Study in Last 10 Years
}

\author{
Ratul Datta ${ }^{1}$, Dr. Tapati Basu ${ }^{2}$ \\ ${ }^{1}$ Ph.D. Research Scholar, ${ }^{2}$ Former Professor, Former HOD and Former Dean of Arts \\ Department of Journalism and Mass Communication, University of Calcutta, Kolkata, West Bengal, India
}

\begin{abstract}
There is no denying the fact that, there is an increasing call for scientists and engineers to engage with the public more and more through mass media for sustainable development throughout the world. The scenario of is somehow different in Asia and African countries in comparison to European and American countries. The study involved a survey of research with selected newspapers of selected countries as sample from those two continents. This study also includes to find the active participation of the scientists through scientific articles, regular columns, post-editorials, letters to the editor etc and hence 28 different major circulated newspapers from 28 countries of Asia and Africa were chosen. There is a great need of policy which enable a higher proportion of younger scientists to get involved in public engagement and the need to reward public engagement activity in the career progression of scientists.
\end{abstract}

Keywords: Mass media, Sustainable development, Science communication, Newspaper, Post Editorials

\section{INTRODUCTION}

This research paper is nothing but a study for understanding the complexity of science news in the newspapers or print media of Asian countries in comparison to African countries in the last 10 years and to understand the comparative study of sustainable development. In this research work, the main objective is to explore the essential cause of the epistemological study of decaying scenario in science communication as an area of specialization in Asian countries in one hand, and the African countries on the other hand. But which continent ia lagging behind, is now a vital question in the platform of development. It gives a brief theoretical understanding of the concept of science and communication to throw a broad light on what constitutes science communicating. This study will help the media professionals and academicians of different regional languages of those multilingual countries and the kind of problems that they are facing in their profession regarding to communicate science and various local scientific issues. As far as coverage of science and technology in mass media is concerned, in developing countries of both the continent, it should be increased in near future significantly, as very fast and rapid developments are taking place. There is no denying the fact that science communication plays a central role in the process of human development. 'Development' to be kept in mind, whatever is the process. This is hypothetical that this ideal situation is prevailing globally. But the actual finding is totally different.

\section{SCIENCE JOURNALISM AND SUSTAIN DEVELOPMENT GOAL}

Journalism and media participation in science conveys reporting about science to the people of that country. It is a parameter of sustainable development. The field typically involves interactions between scientists, journalists, and the public. All three of these groups often criticize science journalism for bias and inaccuracies. On the other hand, the Official Agenda for Sustainable Development adopted on 25 September 2015 has 92 paragraphs, with the main paragraph (51) outlining the 17 Sustainable 
Development Goals and its associated 169 targets. Hence, the aim of a science journalist is to render very detailed, specific, and often jargon-laden information produced by scientists into a form that non-scientists can understand and appreciate, while still communicating the information accurately. The main goals for sustainable development which are somehow related to science journalism are as follows:

1. No Poverty - Both in Asian and African countries, poverty is a big issue. Poverty includes the lack of basic services, like social discrimination education and hence lack of participation in decision making of country's benefits. 2. Zero Hunger - To stop hunger and have food security for an improved nutrition world is a basic need today. Presently 1 in 9 people are under nourished. 3. Good Health and Well-being - Promotion of well being of the people, it is an important target of the media, about how to reduce death-ill people due to pollution of the world. 4 . Quality Education - Good quality and equitable education is needed within the arena of African and Asian countries. Special attempts have been taken at primary and secondary level for ease of education access for both the genders. 5. Gender Equality Empowering women with right to education and health care is a big issue today and it fuels sustainable economical benefit to the humanities at large. 6 . Clean Water and Sanitation - Available of clean water and sanitation for sustainable management. 7 . Affordable and Clean Energy - Easy access of reliable, sustainable, affordable and cost reduced modern technology for all. 8. Decent Work and Economic Growth - Sustainable economic growth for full productive employment for all. 9. Industry, Innovation and Infrastructure - Renovation and industrialization for inclusive growth is needed today for regular employment. 10. Reduced Inequalities Reduce income inequality among the people of countries. 11. Sustainable Cities and Communities Make municipal areas and cities and human settlements more habitable. 12. Responsible Consumption and Production - Ensure sustainable production and consumption systems. 13. Climate Action - Taking necessary steps to reduce climate change and its impact on the society and also promotion of renewable energy. 14. Life Below Water - Sustainable use of the oceans, seas and marine resources for adequate use of physical resources. 15. Life on Land - Sustainable management of forests and to restore land degradation and to maintain and halt biodiversity. 16. Peace,
Justice and Strong Institutions - Strong institutions are needed for sustainable development with peace and justice at every level of the society. 17. Partnerships for the Goals - Strengthen the means of implementation and revitalize the global partnership for sustainable development.

\section{OBJECTIVE}

The main aim and target of this research work is to find out the truth which is hidden and not been discovered yet. Hence the application of scientific procedure is used to find the specific answer of the questions. This research is nothing but an attempt to understand the complexity and use of newest media for science communication and public engagement with scientific sustainable development and its awareness, which is happening around him/her. Compared to Asian and African countries, it is found that world has already experiencing a widespread diffusion of scientific activities. This research has the main target to find the role of mass media to mobilize the people of grass root level to improve scientific temperament and scientific literacy, to test a hypothesis of a causal relationship between variables and also to find the influence of advertisement and political news over scientific news.

\section{LITERATURE REVIEW}

It is very relevant and important to refer briefly and study of previous research work depending on the nature of the problem. Several books, journals on science communications have been cited in my research work. It is found that very small number of people has been studied the problem of science communication globally. Hence, my research work is unique in this respect, within this time frame.

A. Ecquid Novi (2014): 78 science journalists from 38 countries took part in the project, which ran between 2010 and 2012 and is the focus of this article. The aim here is to use this project as a case study and extract from it insights into the professionalization of African and Arab science journalism that are of general relevance - especially concerning the ability of support programmes to build the capacity of journalists to cover science, the importance of establishing newsroom structures for science, and the chances of support programmes helping to overcome the financial difficulties of journalists.

B. Hester du Plessis (2017): In this paper the author tried to demonstrate how the field of science 
communication is complex in application and complicated by cultural-political agendas. With limited access to science communication as a discipline within South African universities, science communication remains within a space where it serves political agendas and remains in danger of being ideologically manipulated. Science communication is progressively echoing the development of science in areas of health (such as with the HIV-AIDS epidemic) in astronomy (the Square Kilometre Array (SKA) project), and in environmental ecology, but these scientific areas remain in the domain of global science with the role players led by global agencies; the public(s) remain as an elite and selectively educated group.

\section{Fernanda Veneu, Luis Henrique Amorim,} Luisa Massarani (2009): In this article, the authors aimed to analyze the process of accommodation of scientific information from its original source - in this case, a scientific article - until the point in which it is transformed into a journalistic article. A first aspect that caught our attention at the beginning of this study was the fact that, in a period of 30 days, we identified 17 coinciding topics, with reports generated from one article provided by the scientific community.

\section{Makerere University, Uganda (2011): The} research suggests that, there are varied reasons for the dearth of science and technology issues in the African media. Foremost among these is that science and technology issues are often considered complex or that journalists in Africa lack specialized knowledge and competence to cover them. What's more, the scientific community hardly trusts journalists because of the fear of being misquoted or quoted out of context. This is despite the fact that the media and the scientific community ought to have a symbiotic relationship (scientists as sources and the media as interpreters and disseminators of the information). This is of course not peculiar to Africa although it demonstrates a worrying trend where issues considered of 'little' public interest, however vital to society, are hardly covered.

\section{RESEARCH METHODOLOGY}

It is a way to systematically solve the research problem. Researchers not only need to know how to develop certain statistical tests or how to apply particular research techniques, but also they need to know which of these methods or techniques are relevant to this research work and which are not and ultimately what they would mean and indicate.

\section{Sample Survey}

For this research work, it is not possible to have all the countries of Asia and Africa as the sample space. Further, it is also too tough to analyze all the news of all countries at a glance. Hence:

\section{Asia}

China, India, Japan, Afghanistan, South Korea, Saudi Arabia, Iran, Pakistan, Bangladesh, Thailand, Russia, North Korea, Indonesia and Israel were chosen.

\section{Africa}

Algeria, Angola, Ethiopia, Ghana, Namibia, Nigeria, Senegal, South Africa, Kenya, Mongolia, Morocco, Tunisia, Sudan and Egypt were chosen.

\section{Research Design}

The time period for this research work were chosen as 2006-2016. Answers to the questionnaires were considered in the last year of the research period.

Total 28 countries were chosen and in each country, 20 respondents were considered to send questionnaire. Hence the sample size or respondent was around 560. Hence this is a research work of 560 variables. Again, for the sample space chosen as different countrybased newspapers all over the world, the dates were considered as every $7^{\text {th }}$ day of every month and multiple of 7 , i.e. $7^{\text {th }}, 14^{\text {th }}, 21^{\text {st }}$ and $28^{\text {th }}$ day of every month. Only English was taken as the language of those newspapers and except India, all other newspapers were collected from their respective websites in pdf format. There are 28 countries in my sample, so for 11 years, 4 days in a month, total sample space, i.e. total no of newspaper becomes 1,232 .

\section{Continent and country-wise Newspaper chosen for research}

For Asian countries: China Daily for China, The Times of India for India, Asahi Shimbun (International Herald Tribune) for Japan, Afghanistan Times Daily for Afghanistan, The Korea Herald for South Korea, Arab News for Saudi Arabia, Tehran Times for Iran, Dawn for Pakistan, The daily Star for Bangladesh, The Nation for Thailand, The Moscow Times for Russia, The Pyongyang Times for North Korea, The Jakarta Post for Indonesia, The Jerusalem Post for Israel were chosen. 
For African countries: Algeria Daily for Algeria, News Time Africa for Angola, The Ethiopian Herald for Ethiopia, Daily Graphic for Ghana, New Era for Namibia, This Day for Nigeria, Xew Media for Senegal, Africa Herald Express for South Africa,
Daily Nation for Kenya, UB Post for Mongolia, MBC Times for Morocco, The Tunis Times for Tunisia, Sudan Tribune for Sudan and Al-Ahram for Egypt were chosen.

\section{RESULTS}

\begin{tabular}{|l|l|l|l|l|l|l|l|l|l|l|l|l|l|l|l|l|}
\hline \multicolumn{10}{|c|}{ Percentage of Space share of Science News in Asian Countries } \\
\hline Chi & Ind & Jap & Thai & Indo & Russia & S.Kor & N.Kor & Bang & Pak & Afghan & S.Arab & Iran & Israe & T \\
\hline 5.8 & 3.6 & 4.6 & 3.9 & 4.1 & 7.5 & 2.1 & 1.2 & 2.5 & 2.0 & 0.9 & 0.8 & 0.8 & 0.8 & $\mathbf{2 . 9}$ \\
\hline
\end{tabular}

\begin{tabular}{|l|l|l|l|l|l|l|l|l|l|l|l|l|l|l|l|}
\hline \multicolumn{10}{|c|}{ Percentage of Space share of Science News in Asian Countries } \\
\hline Alg & Ang & Ethio & Gha & Nami & Nige & Sene & S.Afr & Ken & Mong & Moro & Tuni & Sudan & Egypt & T \\
\hline 5.8 & 3.6 & 4.6 & 3.9 & 4.1 & 7.5 & 2.1 & 1.2 & 2.5 & 2.0 & 0.9 & 0.8 & 0.8 & 0.8 & $\mathbf{1 . 5}$ \\
\hline
\end{tabular}

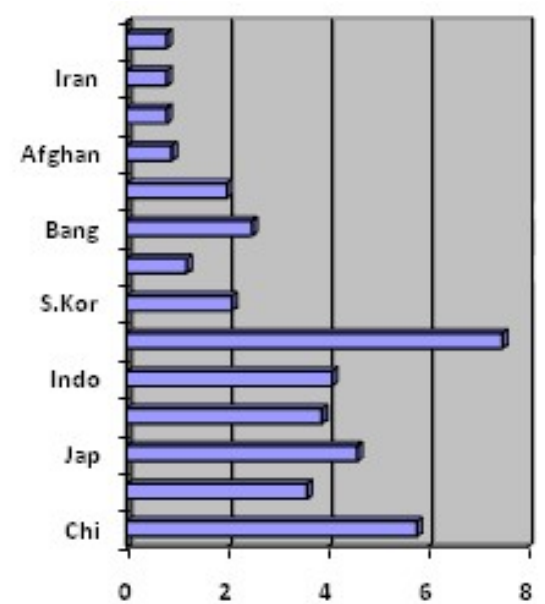

Fig-1 Space share-Science News-Asian Countries

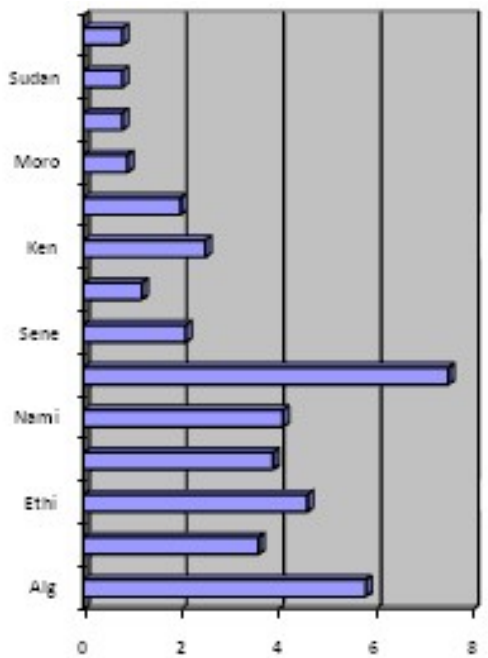

Fig-2 Space share-Science News-Asian Countries



Fig-3 Science News-Asian and African Countries
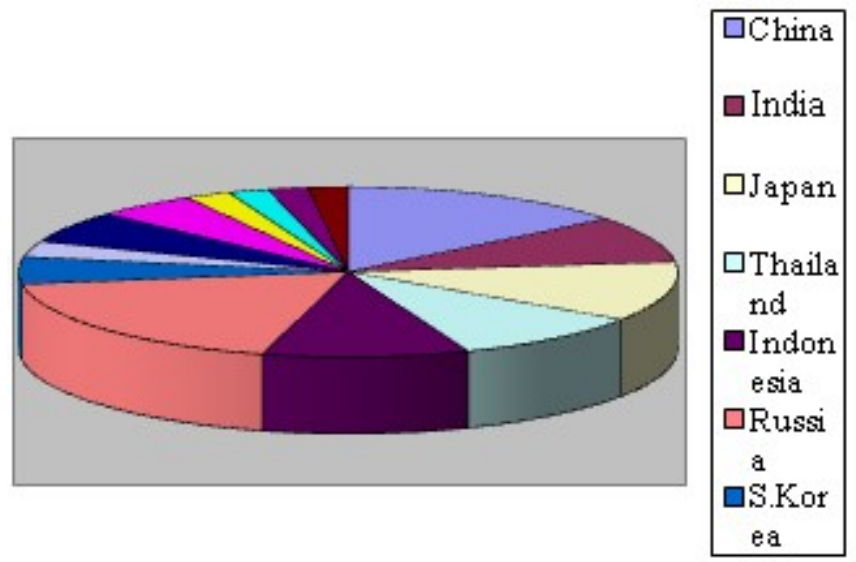

Fig-4 Pie diagram showing comparative analysis of science news in Asian countries



Fig-5 Pie diagram showing comparative analysis of science news in African countries

From the Fig 1, it is found that, in Asian country, Russia is at the $1^{\text {st }}$ position in sharing of space in science news in newspaper followed by China, Japan, Indonesia and India.

From the Fig 2, it is found that, in African country, Nigeria is at the $1^{\text {st }}$ position in sharing of space in science news in newspaper followed by Algeria, Ethiopia, Ghana and then Angola. 
From the Fig 3, it is found that, in space sharing of science news, in print media, in the last 10 years, African countries have 1.5 percent of space share and Asian countries have 2.9 percent space share.

From Fig-4 \& 5 shows the respective space share of African and Asian country for publication of science news in their newspapers in the last 10 years.

\section{CONCLUSION}

This study on science journalism between two continents provides the important feedback that; African countries have less space share than Asian countries in the last 10 years. It is also found that, Russia has largest space share among Asian countries whereas Nigeria has largest space share among African countries. It is also understood that, digital information and communication technologies are only novelty tools that can be used to reinforce scientific temper. More participation means more digital library, more human modernization, more technological mediation and obviously, more literacy. Finally the study would benefit those readers, who follow the content only, but do not post comments.

\section{REFERENCE}

1. Aamoth. D. (2011). Brief History of Skype. New York: Oxford University Press.

2. Balousha, H. (2013). Palestian Youth on Social Media. Gaza Publications.

3. Barneys, S. (2012). Effects of social media on employees, New York: Tag Archive.

4. Basit, A. D. (2013). Side Effects of Social Media and Pakistani Young Generation Pakistan: Pakistan News.

5. Beattie, A. (2013). Social media and its effects on our emotional well being. Canada: NSIGHT Planner at Metro and Freelance Film Journalist.

6. Berkman, S. (2007). Why youth hearts social network sites, Berkman Center for Internet and Society, Harvard University, USA. .

7. Cassidy, E., Britsch, J., Griffin, G., Manolovitz, T., Shen, L., \& Turney, L. (2011). Higher education and emerging technologies: Student usage, preferences, and lessons for library services. Reference \& User Services Quarterly, 50(4), 380-391.
8. Charlton, J., \& Danforth, I. (2007). Distinguishing addiction and high engagement in the context of online game playing. Computers In Human Behaviour,, 23(3), 1531-1548.

9. B. N. Liu, "Grass-root popular science in the context of new medium era: An amateur authors' understandings and experience of popular science writing," Journal of Science Popularization Research, vol. 6, pp. 11-15, Dec. 2012.

10. J. Zhao and L. Wang, "A study on new media and its application in science popularization," Journal of Science Popularization Research, vol. 6, pp. 46-51, Dec. 2012. Philosophy of Science and Technology, Fudan University, China, 2004.

11. D. Y. Zhang, S. L. Tao, and Z. Y. Guo, Introduction to Science Popularization, 1st ed, Beijing China: Peking University Press, 1983, ch. 1, pp. 38.

12. S. K. Tang, "Science Communication Strategy Innovation of Basic Science Disciplines in an Era of Web 2.0," Journal of Science Popularization Research, vol. 5, pp.57-58, Oct. 2012.

13.Z. P. Yin, "The philosophy of science communication studies," Ph.D. dissertation, Dept.

14. Pungente, J. (1989). Media Literacy Resource Guide. Toronto, ON: Ontario Ministry of Education.

15. Tyner, K.R., \& Kolkin, D. (1991). Media and You: An Elementary Literacy Curriculum.

16. Englewood Cli\#s, NJ: Strategies for Media Literacy Inc., Educational Technology Publications.

17. Vasanti, P.N. (n.d.). A national policy could help Indian media scale new heights. Retrieved February 2, 2011, from http://www.livemint.com

18. C.M. Nautiyal, An idea for a workshop, interfacing scientists, communicators and social scientists, Netletter (Sep. 2003), NCSTCNetwork, New Delhi (2003).

19. C.M. Nautiyal, Science Communication: Quo Vadis?, Indian Media Studies Journal 1, No. 1, Satish Serial Publishing House (2006).

20. Baruah, Sanjib (1999). India against itself: Assam and the Politics of Nationality, University of Pennsylvania Press, Pennsylvania. 
21. Dutta, Nandana. (2012). Questions of Identity in Assam: Location, Migration, Hybridity, Sage Publications, Delhi.

22. O'Sullivan, Chris (2011).The News Media and the Resolution of Ethnic Conflict: Ready for the Next Steps? The Global Review of Ethno politics, Vol. 1 , no. 2, p. 54-56.

23. Hussain, Monirul. (2008). Interrogating Development: State, Displacement and Popular Resistance in North-East India, Sage Publications.
24. Misra, Udayan. (1999). Immigration and Identity Transformation in Assam, Economic and Political Weekly, Vol. 34, No. 21.

25. Richardson, J.D. (2005).Framing social identities: The influence of editorial framing on reader attitudes toward affirmative action and African Americans.Communication research. 32(4): 503528. Sage Publications. 